\title{
Decreased Sensitivity of Leptosphaeria maculans to Pyraclostrobin in Alberta, Canada
}

\author{
Yixiao Wang, Alireza Akhavan, Sheau-Fang Hwang, and Stephen E. Strelkov ${ }^{\dagger}$ \\ Department of Agricultural, Food and Nutritional Science, University of Alberta, Edmonton, AB T6G 2P5, Canada
}

\begin{abstract}
Leptosphaeria maculans, the causal agent of blackleg of canola (Brassica napus), can be managed with pyraclostrobin and other strobilurin fungicides. Their frequent application, however, poses a risk for the development of insensitivity in fungal populations. A collection of $L$. maculans single-spore isolates recovered from infected canola stubble in Alberta, Canada, in 2016 was evaluated for its pyraclostrobin sensitivity. In conventional growth plate assays, the concentration of pyraclostrobin required to inhibit fungal growth by $50 \%\left(\mathrm{EC}_{50}\right)$ was determined to be $0.28 \mathrm{mg} / \mathrm{liter}$ in a subset of 38 isolates. This $\mathrm{EC}_{50}$ was four times greater than the mean $\mathrm{EC}_{50}(0.07 \mathrm{mg} / \mathrm{liter})$ of baseline isolates collected in 2011. Two hundred sixty-three isolates were screened further with two discriminatory doses of 0.28 and $3.5 \mathrm{mg} /$ liter of pyraclostrobin, resulting in growth inhibition

values ranging from 16 to $82 \%$ and 41 to $100 \%$, respectively. In microtiter plate assays with the same isolates, the mean $\mathrm{EC}_{50}$ was determined to be $0.0049 \mathrm{mg} / \mathrm{liter}$, almost 3.3 times greater than the mean $\mathrm{EC}_{50}$ $(0.0015 \mathrm{mg} /$ liter $)$ of the baseline isolates. The sensitivity of the isolates was also evaluated in microtiter plate assays with discriminatory doses of 0.006 and $0.075 \mathrm{mg} /$ liter of pyraclostrobin, resulting in inhibition values ranging from 20 to $88 \%$ and 49 to $100 \%$, respectively. This is the first report of isolates of L. maculans with increased insensitivity to pyraclostrobin in Canada, suggesting the need for improved fungicide stewardship.

Keywords: blackleg of canola, fungicide resistance, sensitivity, Leptosphaeria maculans, pyraclostrobin
\end{abstract}

Blackleg (Phoma stem canker) caused by Leptosphaeria maculans (Desm.) Ces. \& de Not. is the most economically important disease of canola (syn. rapeseed, Brassica napus L.) worldwide (Fitt et al. 2006; Howlett 2004; West et al. 2001). The disease can cause significant yield losses and is a major constraint to canola production (Gugel and Petrie 1992; Hwang et al. 2016). Blackleg emerged as a major production challenge for western Canadian canola growers in the 1970s and 1980s, with the first blackleg-resistant cultivars becoming available in the early 1990s (Kutcher et al. 2011). Blackleg-resistant cultivars enabled farmers to manage the disease quite successfully, particularly when these varieties were combined with a 4-year crop rotation (Kutcher et al. 2013). In recent years, however, high economic returns, market opportunities, and cultivar improvements have led to the more intense production of canola and shorter crop rotations in western Canada (Kutcher et al. 2013). From 2010 to 2015, blackleg incidence in this region increased (Zhang and Fernando 2017), resulting in renewed interest in the management of this disease (Kutcher et al. 2011).

On the prairies of western Canada (Alberta, Saskatchewan, and Manitoba), fungicides represent an important tool in blackleg management. There are three registered active ingredients, including propiconazole, azoxystrobin, and pyraclostrobin (Canola Council of Canada 2017). Azoxystrobin and pyraclostrobin are broad-spectrum strobilurin fungicides. The strobilurins are single-site mode-of-action chemicals, also known as quinine outside inhibitors (QoIs) (Bartlett et al. 2002). These fungicides bind to the Qo site of the cytochrome $b c 1$ enzyme complex (complex III) of the mitochondria, inhibiting mitochondrial respiration (Gisi et al. 2002). This prevents the formation of adenosine triphosphate and results in an energy deficiency in

${ }^{\dagger}$ Corresponding author: S. E. Strelkov; stephen.strelkov@ualberta.ca

Funding: The authors acknowledge the financial support received for this work from the Canola Council of Canada, Agriculture and Agri-Food Canada, Alberta Canola, and other industry partners.

The author(s) declare no conflict of interest.

Accepted for publication 11 March 2020.

(C) 2020 The American Phytopathological Society the fungus (Gisi et al. 2002). Strobilurin fungicides are particularly effective at inhibiting spore germination, which is an energydemanding stage of fungal development (Bartlett et al. 2002). Inhibition of the respiratory electron transport chain also results in the build-up of reactive oxygen species, which are very damaging to cells and hence contribute to fungal control (Inoue et al. 2012).

Pyraclostrobin has been used widely on various crops in Canada since 2002 (Health Canada 2003; Government of Canada, Health Canada Pest Management Regulatory Agency 2011) and is the active ingredient in the commonly applied fungicide Headline EC (pyraclostrobin, $250 \mathrm{~g} /$ liter; BASF 2018). This product was registered on canola in 2010 and was first used in 2011. Because of the site-specific activity of pyraclostrobin, G143A, G137R, and F129L mutations in cytochrome $b$ can result in the appearance of fungicide-resistant or -tolerant fungal strains (Vincelli 2002). In the case of $L$. maculans, no pyraclostrobin resistance or specific mutation has been reported to date. The repeated application of pyraclostrobin could, however, select for a fungicide-resistant subpopulation of $L$. maculans, as has been reported for other fungal pathogens (Forcelini et al. 2016; Vincelli 2002).

Fraser et al. (2017) examined the pyraclostrobin sensitivity of a collection of L. maculans isolates made from Alberta in 2011, the year following the registration of this fungicide on canola. All of the isolates tested in this earlier study were sensitive to pyraclostrobin, although the potential for future shifts in sensitivity was noted (Fraser et al. 2017). Periodic monitoring is important for proper fungicide stewardship and ensuring continued product efficacy. In this context and in the present study, the fungicide sensitivity of an L. maculans collection from Alberta made in 2016, after 5 years of pyraclostrobin application on canola, was investigated in growth plate and microtiter plate assays.

\section{Materials and Methods}

Collection and preparation of single-spore isolates. A collection of $251 \mathrm{~L}$. maculans single-spore isolates was obtained from infected canola stubble from 18 fields surveyed throughout Alberta in 2016. Stubble was collected from a $1-\mathrm{m}^{2}$ area at each of five points along the arms of ' $W$ ' sampling pattern in each field, with the sampling points spaced at least $5 \mathrm{~m}$ apart. Single-spore isolations were made following the method of Rong et al. (2015) and stored as pycnidiospores in $1.5-\mathrm{ml}$ microcentrifuge tubes at $-80^{\circ} \mathrm{C}$ in sterilized $20 \%$ glycerol. 
The identity of these isolates as L. maculans was confirmed by means of a polymerase chain reaction assay with $\beta$-tubulin-based primers (Rong et al. 2015). Twelve single-spore isolates obtained from infected canola stubble in Alberta in 2011 (Fraser et al. 2017) were also included in this study and regarded as baseline isolates.

Conventional growth plate assays. Determining the mean $E C_{50}$. A subset of 38 L. maculans isolates collected in 2016 was randomly selected from the entire collection and used to determine the effective concentration of pyraclostrobin required to inhibit mycelial growth by $50 \%\left(\mathrm{EC}_{50}\right)$. The $\mathrm{EC}_{50}$ of the 12 isolates collected in 2011, previously analyzed by Fraser et al. (2017), also was determined. To revive the isolates, stored pycnidiospores were removed from storage in the microcentrifuge tubes and placed on Petri dishes (10-cm diameter) filled with V8 growth medium (composition per liter: $850 \mathrm{ml}$ of distilled water, $150 \mathrm{ml}$ of V8 Original Vegetable Juice, $1.5 \mathrm{~g}$ of $\mathrm{CaCO}_{3}$, and $15.0 \mathrm{~g}$ of agar). After 10 days, $6-\mathrm{mm}$ plugs of the developing colonies were transferred to fresh V8 medium amended with different concentrations of pyraclostrobin. Briefly, a fungicide stock solution was prepared by adding $1 \mathrm{ml}$ of Headline $250 \mathrm{EC}$ (pyraclostrobin, $250 \mathrm{~g} / \mathrm{liter}$; BASF Canada, Mississauga, ON) to $49 \mathrm{ml}$ of sterilized distilled water, and it was used to obtain final concentrations of active ingredient in the amended plates of $0,0.0125,0.025,0.125$, $0.25,0.375,0.5,0.625,0.75$, and $0.875 \mathrm{mg} / \mathrm{liter}$ by serial dilution. The appropriate amounts of fungicide were added shortly after autoclaving when the medium had cooled to 50 to $60^{\circ} \mathrm{C}$. Although Fraser et al. (2017) did not report any significant difference between the $\mathrm{EC}_{50}$ values of isolates tested in the presence or absence of salicylhydroxamic acid (SHAM), $0.1 \mathrm{~g} /$ liter of this chemical was included in the present assays as a precaution against alternative respiration (Wood and Hollomon 2003). The Petri dishes were placed under fluorescent lighting at $20 \pm 2{ }^{\circ} \mathrm{C}$ for a period of 10 days, at which time two orthogonal measurements of colony diameter (growth) were made using a digital caliper and averaged. The experiment was arranged in a completely randomized design with five replicates (Petri dishes) per treatment and was repeated independently. The percentage of radial growth inhibition relative to the unamended control was determined using the following equation: [(average growth on unamended medium - growth on amended medium)/average growth on unamended medium] $\times 100$.
Testing the pyraclostrobin sensitivity of $\mathrm{L}$. maculans isolates. To evaluate the sensitivity of $L$. maculans, two discriminatory doses of pyraclostrobin were used to screen a collection of 251 singlespore isolates from 2016 and 12 single-spore isolates from 2011. The dosages were $4 \times$ and $50 \times$ the $\mathrm{EC}_{50}$ value of the 12 isolates from 2011. Therefore, V8 growth medium containing pyraclostrobin at 0.28 or $3.5 \mathrm{mg} / \mathrm{liter}$ and SHAM at $0.1 \mathrm{~g} / \mathrm{liter}$ was used to determine the sensitivity of the examined fungal isolates. Inoculation of the cultures and preparation of the medium in Petri dishes were as described above. The Petri dishes were incubated under fluorescent lighting at $20 \pm 2{ }^{\circ} \mathrm{C}$ for 10 days. Two orthogonal measurements of the mycelial growth of each isolate were made and averaged using a digital caliper, with inhibition of radial growth expressed as a percentage of the unamended controls as described above. The treatments included four replicates (Petri dishes) for each isolate plus four control replicates that did not contain any fungicide. Treatments were arranged in a completely randomized design, and the experiment was independently repeated.

Testing minimum inhibitory dose of $\mathrm{L}$. maculans isolates. An isolate found to have a growth inhibition value of $<50 \%$ was evaluated further with two sets of discriminatory doses. The first set included doses of $4.9,7$, and $10.5 \mathrm{mg} /$ liter of pyraclostrobin, equivalent to $70 \times, 100 \times$, and $150 \times$ the mean $\mathrm{EC}_{50}$ of the isolates collected in 2011 , respectively. The second set of discriminatory doses included $14,19.6,28$, and $42 \mathrm{mg} /$ liter of pyraclostrobin, equivalent to $50 \times$, $70 \times, 100 \times$, and $150 \times$ the $\mathrm{EC}_{50}$ of the isolates collected in 2016 . Tests were conducted as above in V8 medium containing SHAM at $0.1 \mathrm{~g} /$ liter. Similarly, two orthogonal measurements of the mycelial growth of each isolate were made and averaged using a digital caliper, with inhibition of radial growth expressed as a percentage of the unamended controls as described earlier. The treatments included four replicates (Petri dishes) for each isolate plus four control replicates that did not contain any fungicide.

Microtiter plate assays. Determining the mean $E C_{50}$. The same isolates used in the conventional growth plate assays were included in the microtiter plate assays. Fifty isolates including 12 isolates collected in 2011 and 38 isolates collected in 2016 were used to determine the mean $\mathrm{EC}_{50}$. In order to increase spore density, the spores were collected and immersed in YBA medium (composition per liter

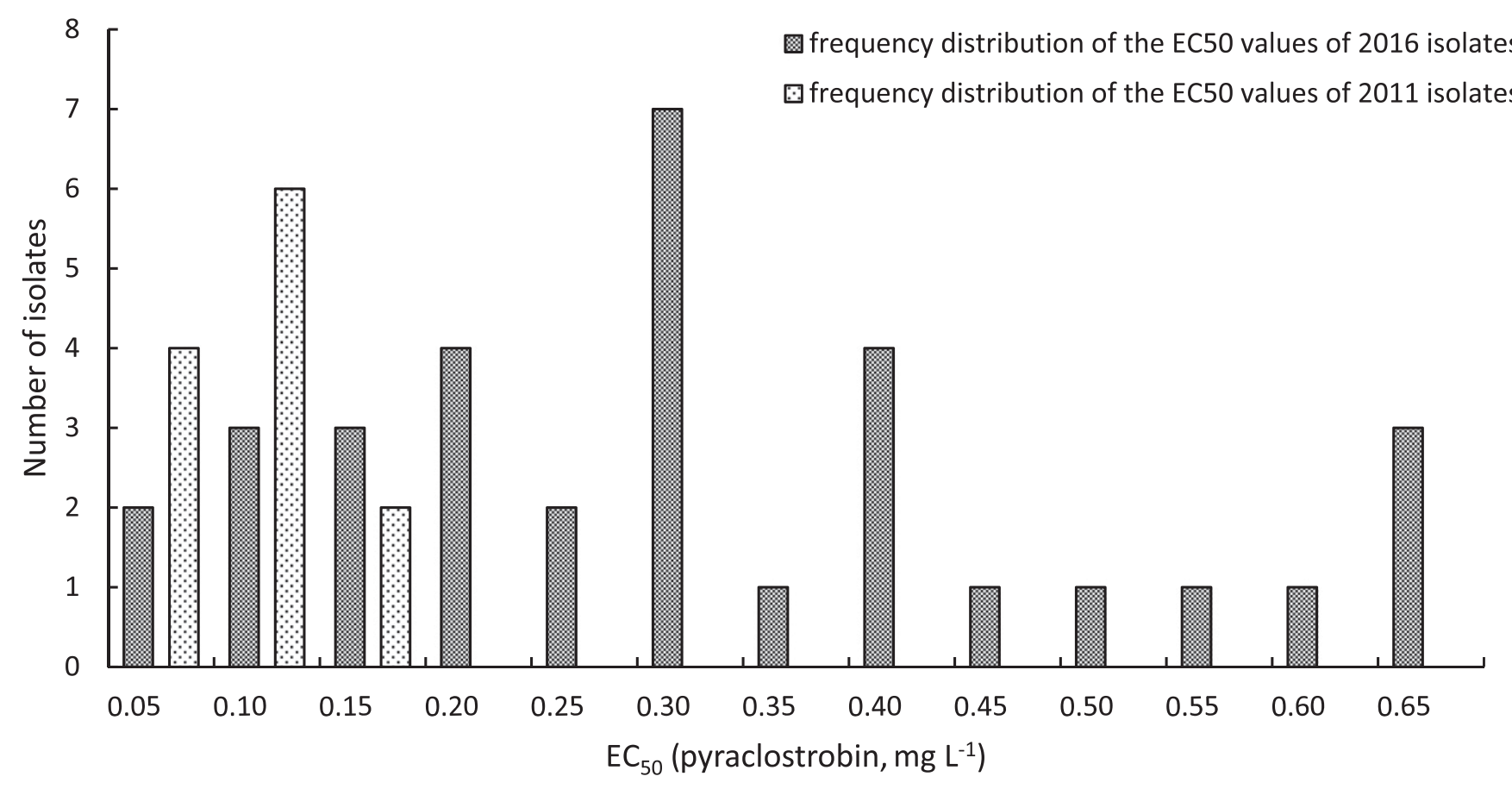

Fig. 1. Frequency distribution of the effective concentration of pyraclostrobin needed to inhibit mycelial growth by $50 \%$ ( $\mathrm{EC}_{50}$ ) in 33 isolates of Leptosphaeria maculans collected in 2016 and 12 isolates collected in 2011 from Alberta, Canada. Values were determined based on conventional growth plate assays. Individual isolates are grouped in class intervals of $0.05 \mathrm{mg} / \mathrm{liter}$. 
of sterilized water: $20 \mathrm{~g}$ of yeast extract, $20 \mathrm{~g}$ of Bacto peptone, and $40 \mathrm{~g}$ of sodium acetate). Streptomycin ( $100 \mathrm{mg} / \mathrm{liter})$ was added to the medium to avoid bacterial contamination. YBA medium is relatively low in nutrients, so the fungus cannot gain sufficient energy to undergo alternative respiration while still obtaining sufficient nutrients for fungal growth (Spiegel and Stammler 2006). Hence, SHAM was not included in the YBA medium. The fungal spore concentration was adjusted to $2 \times 10^{4}$ spores $/ \mathrm{ml}$. Fifty microliters of the spore suspension, containing about 1,000 spores, was transferred into each well of a 96-well microtiter plate, which contained $50 \mu$ l of the fungicide solution of different concentrations prepared in YBA medium. Formulated Headline 250 EC fungicide was diluted to achieve the

Table 1. The effective concentration of pyraclostrobin needed to inhibit mycelial growth by $50 \%\left(\mathrm{EC}_{50}\right)$ in a conventional growth plate assay for 12 isolates of Leptosphaeria maculans originally collected in 2011 (Fraser et al. 2017)

\begin{tabular}{lcc}
\hline Isolate & $\begin{array}{c}\mathbf{E C}_{\mathbf{5 0}} \text { values determined in } \\
\text { the current study }\end{array}$ & $\begin{array}{c}\mathbf{E C}_{\mathbf{5 0}} \text { values determined by } \\
\text { Fraser et al. (2017) }\end{array}$ \\
\hline $11 \mathrm{C} 78103$ & 0.02 & 0.07 \\
$11 \mathrm{C} 78301$ & 0.05 & 0.05 \\
$11 \mathrm{C} 78384$ & 0.03 & 0.02 \\
$11 \mathrm{C} 78401$ & 0.09 & 0.04 \\
$11 \mathrm{P} 125062$ & 0.07 & 0.13 \\
1 P125232 & 0.10 & 0.08 \\
11P125384 & 0.08 & 0.04 \\
11S54201 & 0.05 & 0.04 \\
11S54041 & 0.09 & 0.03 \\
11W189011 & 0.11 & 0.17 \\
11L999014 & 0.05 & 0.17 \\
11L999241 & 0.06 & 0.24 \\
Average & 0.07 & 0.09
\end{tabular}

${ }^{\text {a }}$ A paired $t$ test indicated that there was no significant difference between the mean $\mathrm{EC}_{50}$ values determined by Fraser et al. (2017) and in the current study $(P=0.29)$ end concentrations, with the $\mathrm{EC}_{50}$ determined based on 12 concentrations of pyraclostrobin: 0 (control), $0.0005,0.001,0.0015,0.002$, $0.0025,0.003,0.005,0.01,0.015,0.05$, and $0.15 \mathrm{mg} / \mathrm{liter}$. The combined solution was mixed thoroughly in the microtiter plate. Experiments were arranged in a completely randomized design with four replicate wells assigned for each fungicide concentration/isolate combination. The entire experiment was independently repeated. The plates were incubated for 7 days at $18^{\circ} \mathrm{C}$ in darkness. The endpoint optical density of pycnidiospore germination was measured with a spectrophotometer (BioTek, Winooski, VT) at a wavelength of $405 \mathrm{~nm}$ for the initial and final readings. For each isolate and concentration, final values for absorbance were obtained by subtracting the values of the initial reading from those of the final reading, and growth inhibition was calculated as 1 - (absorption for each treatment/absorption of control) and presented as a percentage.

Testing the pyraclostrobin sensitivity of $\mathrm{L}$. maculans isolates. Two discriminatory doses of pyraclostrobin were used to screen 251 single-spore isolates from 2016 and 12 single-spore isolates from 2011. To be consistent with the conventional growth plate assays, the discriminatory doses were $4 \times$ and $50 \times$ the $\mathrm{EC}_{50}$ value obtained for the isolates collected in 2011. Therefore, medium containing concentrations of 0 (control), 0.006 , and $0.075 \mathrm{mg} /$ liter of pyraclostrobin were evaluated. Briefly, after an incubation period of 7 days at $18^{\circ} \mathrm{C}$ in darkness, fungal density was measured at a wavelength of $405 \mathrm{~nm}$. The growth inhibition was calculated as above. The experiment was arranged in a completely randomized design with treatments replicated four times for each isolate, and the entire experiment was repeated.

Testing minimum inhibitory dose of $\mathrm{L}$. maculans isolates. An isolate with a growth inhibition value $\sim 50 \%$ in the microtiter plate assays was evaluated further with two sets of discriminatory doses (this was the same isolate that had a growth inhibition value $<50 \%$ in the growth plate assays). The first set included doses of 0.105 , 0.15 , and $0.225 \mathrm{mg} /$ liter of pyraclostrobin, corresponding to $70 \times, 100 \times$, and $150 \times$ the $\mathrm{EC}_{50}$ of the isolates collected in 2011 , respectively. The second set included $0.245,0.343,0.49$, and

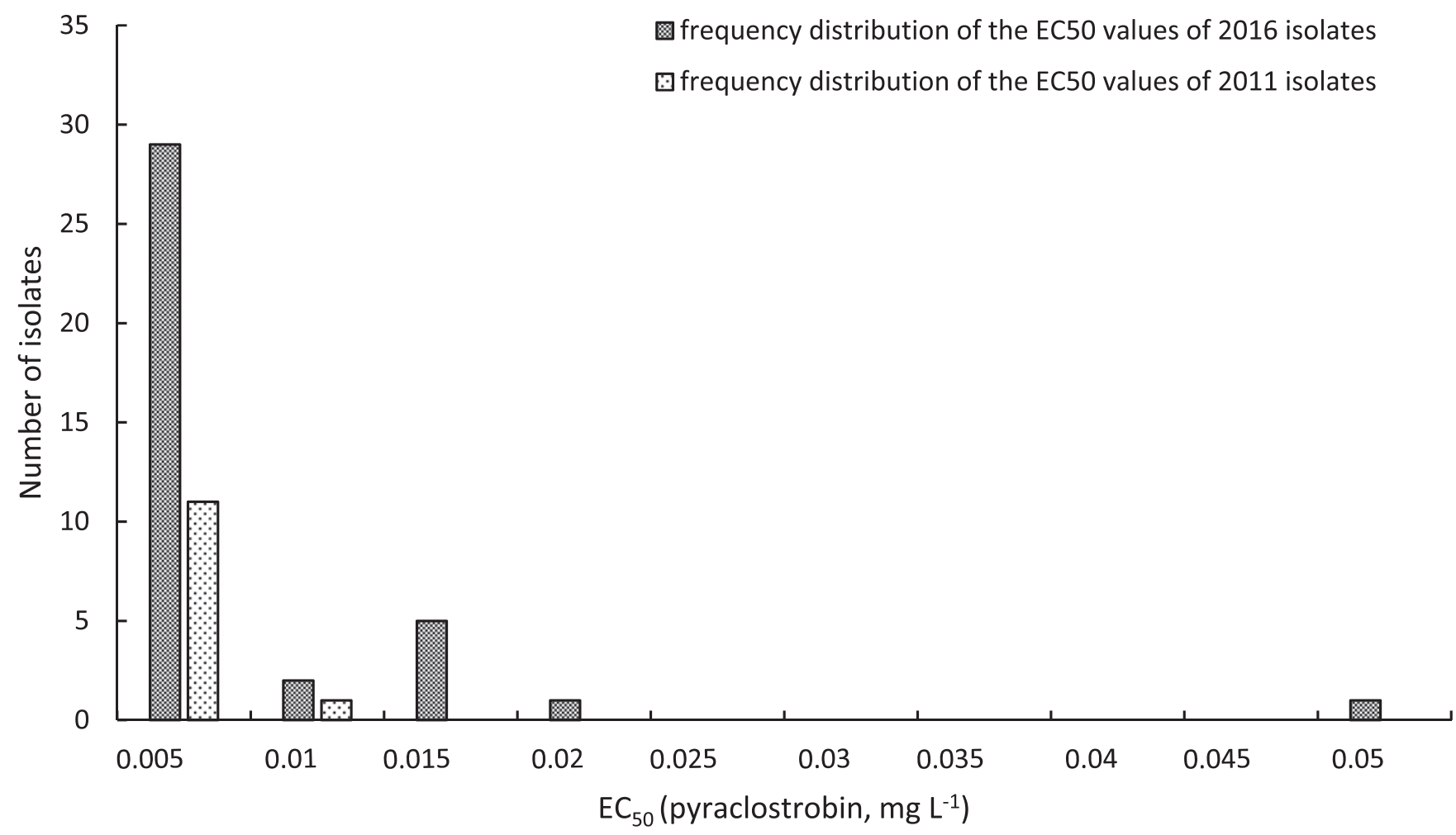

Fig. 2. Frequency distribution of the effective concentration of pyraclostrobin needed to inhibit mycelial growth by $50 \%$ ( $E C_{50}$ ) in 38 isolates of Leptosphaeria maculans collected in 2016 and 12 isolates collected in 2011 from Alberta, Canada. Values were determined based on microtiter plate assays. Individual isolates are grouped in class intervals of 0.005 $\mathrm{mg} / \mathrm{liter}$. 
$0.735 \mathrm{mg} / \mathrm{liter}$ of pyraclostrobin, equivalent to $50 \times, 70 \times, 100 \times$, and $150 \times$ the $\mathrm{EC}_{50}$, respectively, of the isolates collected in 2016 . The assays were conducted as described above for the other microtiter plate assays, with fungal density and growth inhibition also determined in the same manner. The treatments included four replicates for each isolate plus four control replicates that did not contain any fungicide.

Data analysis. Data were analyzed with R: A Language and Environment for Statistical Computing (R Core Team 2013). The normality of the $\mathrm{EC}_{50}$ values for $50 \mathrm{~L}$. maculans isolates (12 isolates from 2011 and 38 isolates from 2016) was evaluated with the Shapiro-Wilk test using the statistical package shapiro.test. The homogeneity of variance was tested using the Levene test (LeveneTest package). To assess the $\mathrm{EC}_{50}$ concentration, a $\log 10$-transformed fungicide concentration was employed to linearize fungal growth inhibition data, and a regression line was calculated. The $\mathrm{EC}_{50}$ values for each isolate were calculated accordingly, and all values were averaged to obtain the mean $\mathrm{EC}_{50}$. The mean $\mathrm{EC}_{50}$ values of the isolates collected in 2016 and 2011 were compared with a two-sided $t$ test. In order to ensure the reproducibility of the data, the mean $\mathrm{EC}_{50}$ values of the isolates from 2011, as determined in the current study, were compared with the corresponding values calculated by Fraser et al. (2017) using a two-sided paired $t$ test. The mean growth inhibition values of all 263 isolates included in the discriminatory dose experiments (growth plate and microtiter plate assays) are displayed in histograms. The distribution of growth inhibition of the 263 isolates in the growth plate and microtiter plate assays was compared using the Kolmogorov-Smirnov test.

\section{Results}

Determination of $\mathbf{E C}_{\mathbf{5 0}}$ values of baseline isolates. Conventional growth plate assays. In the conventional growth plate assays, the $\mathrm{EC}_{50}$ values of the 12 isolates collected in 2011 ranged from 0.02 to $0.11 \mathrm{mg} / \mathrm{liter}$, with a mean of $0.07 \mathrm{mg} / \mathrm{liter}$ (Fig. 1; Table 1). A two-sided paired $t$ test revealed no significant difference between

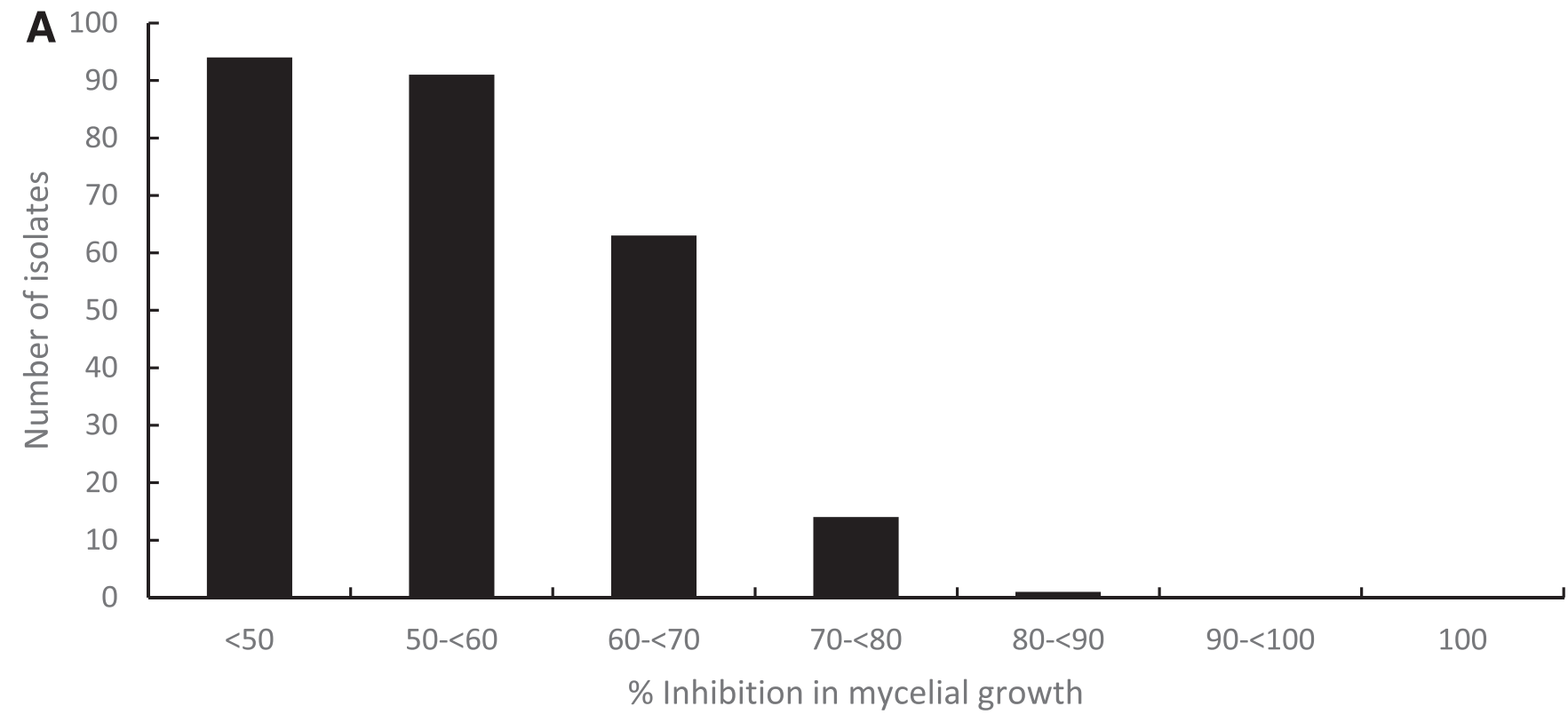

B

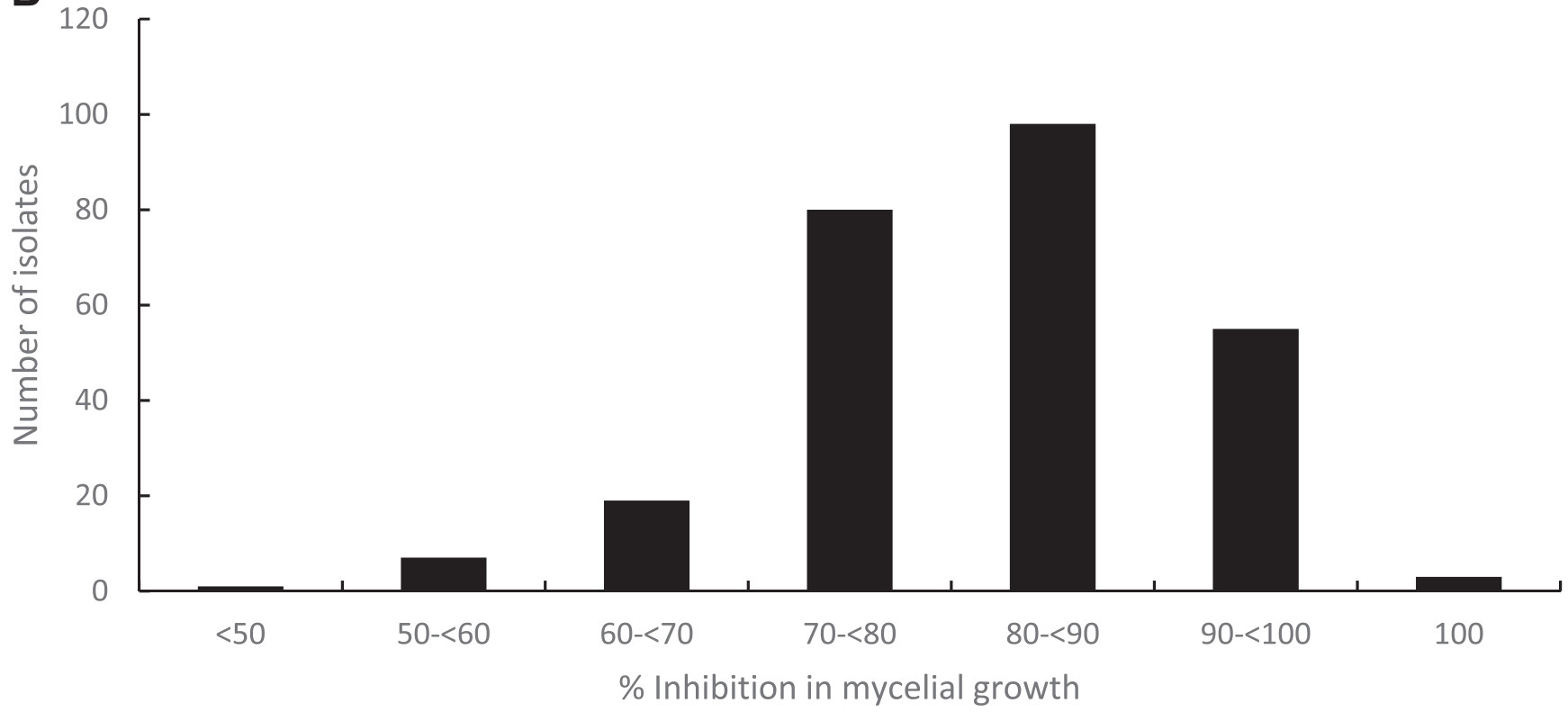

Fig. 3. Frequency distribution of the inhibition of mycelial growth in 263 Leptosphaeria maculans isolates tested with a discriminatory dose of pyraclostrobin ( $0.28 \mathrm{mg} /$ liter) representing $4 \times$ the $\mathrm{EC}_{50}$ for baseline isolates collected in 2011 (A), and a discriminatory dose of pyraclostrobin ( $3.5 \mathrm{mg} /$ liter) representing $50 \times$ the $\mathrm{EC}_{50}$ for baseline isolates collected in 2011 (B), based on conventional growth plate assays. The inhibition of mycelial growth is expressed as a percentage relative to a control treatment with no pyraclostrobin included. 
$\mathrm{EC}_{50}$ values calculated in the current study and those calculated by Fraser et al. (2017) for the same set of isolates $(P=0.29)$ (Table 1). The $\mathrm{EC}_{50}$ values of the 38 isolates collected in 2016 ranged from 0.03 to $0.64 \mathrm{mg} / \mathrm{liter}$, with a mean of $0.28 \mathrm{mg} / \mathrm{liter}$ (Fig. 1). Five of these isolates had predicted $\mathrm{EC}_{50}$ values greater than the maximum concentration of fungicide employed; therefore, to avoid out-ofrange estimates, their estimated $\mathrm{EC}_{50}$ values were excluded from the calculation of the mean $\mathrm{EC}_{50}$ for the 2016 isolates (and only the remaining 33 isolates were used).

Microtiter plate assays. In the microtiter plate assays, the $\mathrm{EC}_{50}$ values of the L. maculans isolates collected in 2011 ranged from 0.0001 to $0.0066 \mathrm{mg} / \mathrm{liter}$, with a mean of $0.0015 \mathrm{mg} /$ liter (Fig. 2) and a left-skewed distribution. The $\mathrm{EC}_{50}$ values of the isolates collected in 2016 ranged from 0.0002 to $0.0489 \mathrm{mg} / \mathrm{liter}$, with a mean of $0.0049 \mathrm{mg} /$ liter (Fig. 2).

Pyraclostrobin sensitivity of $L$. maculans isolates. Conventional growth plate assays. Two hundred fifty-one L. maculans isolates collected from Alberta in 2016, along with another 12 isolates collected in 2011, were assessed for pyraclostrobin sensitivity. When tested with the lower $(0.28 \mathrm{mg} / \mathrm{liter})$ of the two discriminatory doses, growth inhibition of the 263 isolates ranged from 15.7 to $82 \%$, relative to the control treatment (no pyraclostrobin). Ninety-four (36\%) of the isolates had a growth inhibition $<50 \%, 91(35 \%)$ had a growth inhibition of 50 to $<60 \%, 63(24 \%)$ isolates had a growth inhibition of 60 to $<70 \%, 14(5 \%)$ had a growth inhibition of 70 to $<80 \%$, and one isolate had a growth inhibition of 80 to $<90 \%$. No isolate had a growth inhibition $>90 \%$ (Fig. 3A). The 12 isolates from 2011 all had a growth inhibition $>50 \%$. When tested with the second (higher) discriminatory dose $(3.5 \mathrm{mg} / \mathrm{liter})$ of pyraclostrobin, one isolate had a growth inhibition of $<50 \%$, seven $(3 \%)$ had a growth inhibition of 50 to $<60 \%, 19(7 \%)$ had a growth inhibition of 60 to $<70 \%, 80$ $(30 \%)$ had a growth inhibition of 70 to $<80 \%, 98(37 \%)$ had a growth inhibition of 80 to $<90 \%, 55(21 \%)$ had a growth inhibition of 90 to $<100 \%$, and three (1\%) isolates had a growth inhibition of $100 \%$

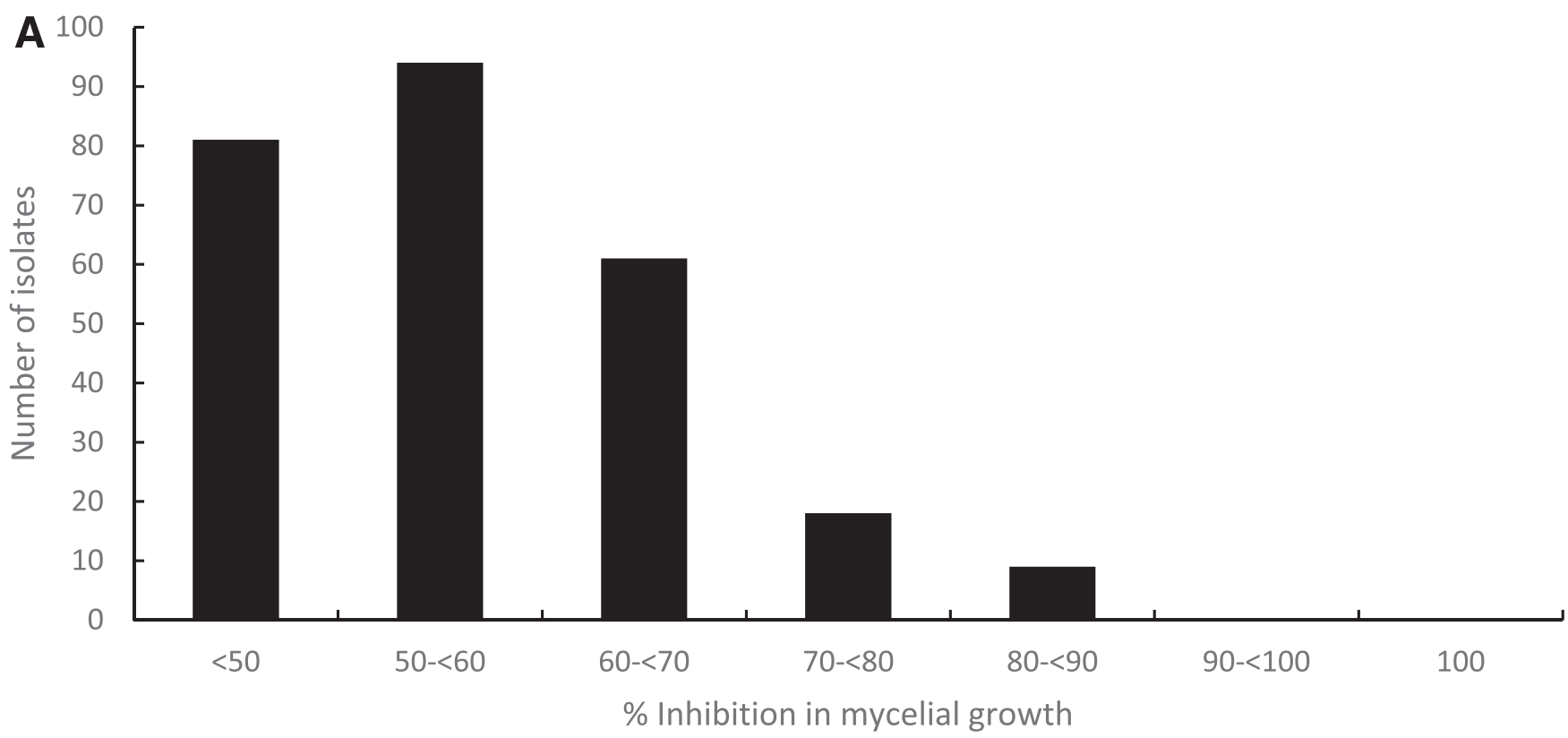

B

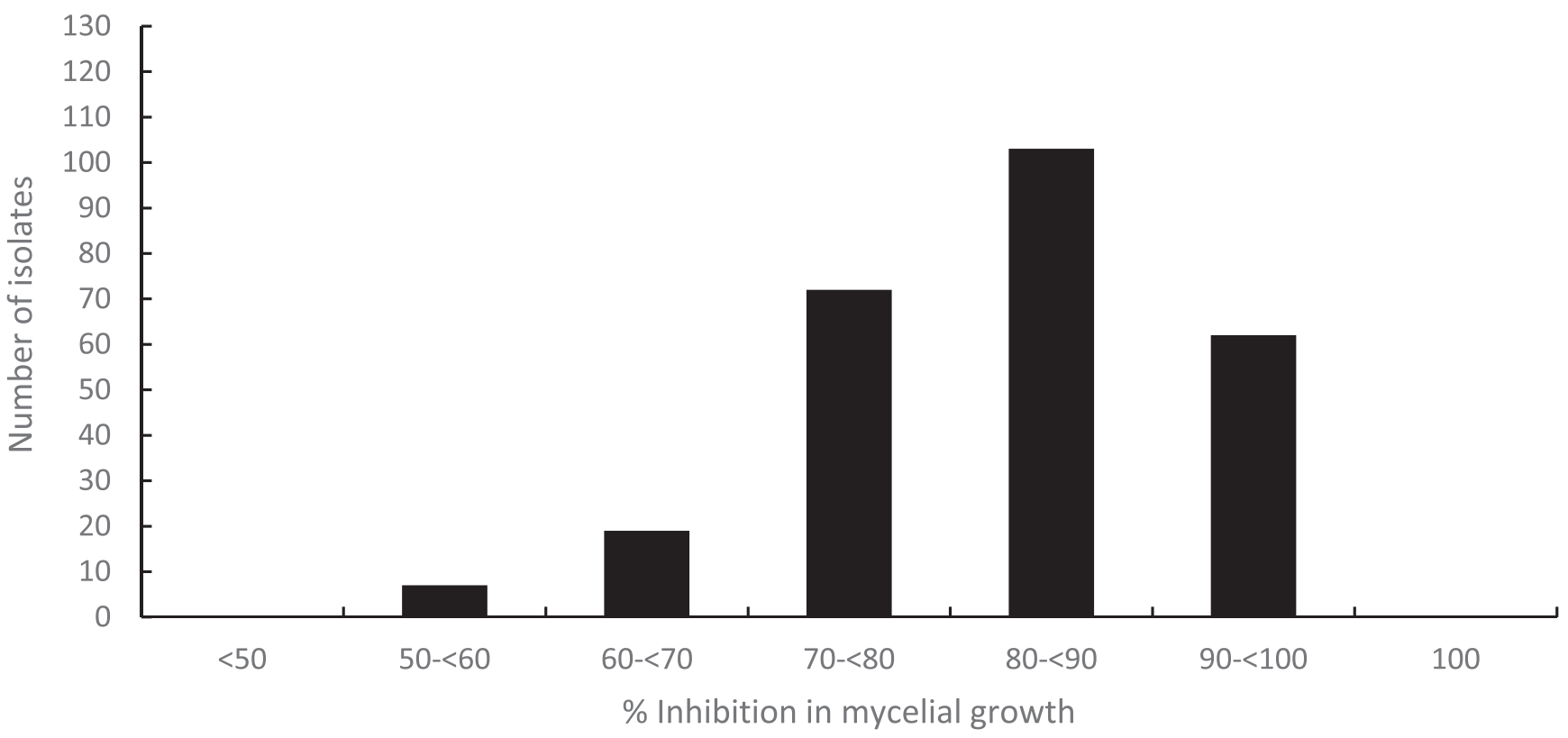

Fig. 4. Frequency distribution of the inhibition of mycelial growth in 263 Leptosphaeria maculans isolates tested with a discriminatory dose of pyraclostrobin $(0.006 \mathrm{mg} /$ liter) representing $4 \times$ the $\mathrm{EC}_{50}$ for baseline isolates collected in 2011 (A), and a discriminatory dose of pyraclostrobin ( $0.075 \mathrm{mg} /$ liter) representing $50 \times$ the $\mathrm{EC}_{50}$ for baseline isolates collected in 2011 (B), based on microtiter plate assays. The inhibition of mycelial growth is expressed as a percentage relative to a control treatment with no pyraclostrobin included. 
(Fig. 3B). The growth inhibition of the 263 isolates ranged from 40.9 to $100 \%$, relative to controls that had not been treated with pyraclostrobin. The 12 isolates from the 2011 collection were all in the highly sensitive category (inhibition $>90 \%$ ).

Microtiter plate assays. In the presence of $0.006 \mathrm{mg} / \mathrm{liter}$ of pyraclostrobin ( $4 \times$ the mean $\mathrm{EC}_{50}$ of the L. maculans isolates collected in 2011), growth inhibition of the 263 isolates ranged from 20 to $87.8 \%$, relative to the control treatment with no pyraclostrobin. Eighty-one (31\%) isolates had a growth inhibition of $<50 \%, 94(36 \%)$ had a growth inhibition of 50 to $<60 \%, 61(23 \%)$ had a growth inhibition of 60 to $<70 \%, 18(7 \%)$ had a growth inhibition of 70 to $<80 \%$, and nine (3\%) isolates had a growth inhibition of 80 to $<90 \%$. No isolates had a growth inhibition $>90 \%$ (Fig. 4A). At the higher discriminatory dose of $0.075 \mathrm{mg} /$ liter of pyraclostrobin $\left(50 \times\right.$ the $\mathrm{EC}_{50}$ of the isolates collected in 2011), seven (3\%) isolates had a growth inhibition of 50 to $<60 \%, 19(7 \%)$ had a growth inhibition of 60 to $<70 \%$, $72(27 \%)$ had a growth inhibition of 70 to $<80 \%, 103(39 \%)$ had a growth inhibition of 80 to $<90 \%$, and $62(24 \%)$ isolates had a growth inhibition of 90 to $<100 \%$ (Fig. 4B). Growth inhibition ranged from 48.8 to $99.5 \%$ across the 263 isolates, relative to the control treatment with no pyraclostrobin.

A comparison, using the Kolmogorov-Smirnov test, of the distribution of growth inhibition of the 263 isolates in the conventional growth plate versus microtiter plate assays indicated that there was no significant difference $(P=0.22)$ at the $4 \times \mathrm{EC}_{50}$ discriminatory dose, with the data left-skewed in both assays. At the $50 \times \mathrm{EC}_{50}$ discriminatory dose, the results from both assays exhibited a right-skewed distribution and also were not significantly different $(P=0.72)$.

Minimum inhibitory concentration of $\mathrm{L}$. maculans isolates. The pyraclostrobin sensitivity of isolate 16CW239002, which had growth inhibition values of $<50 \%$ and $\sim 50 \%$, respectively, in the growth plate and microtiter plate assays, was evaluated further with higher concentrations of the fungicide. In a growth plate assay to evaluate the minimum inhibitory concentration, the percent growth inhibition of this isolate increased to $>50 \%$ at $4.9 \mathrm{mg} /$ liter of pyraclostrobin (70) the $\mathrm{EC}_{50}$ of the isolates collected in 2011), and it did not grow at $19.6 \mathrm{mg} / \mathrm{liter}$ of pyraclostrobin $\left(280 \times\right.$ and $70 \times$ the $\mathrm{EC}_{50}$ of the isolates from 2011 and 2016, respectively) (Table 2). Similarly, in a microtiter plate assay to evaluate the minimum inhibitory concentration of this isolate, the percent growth inhibition increased to $>50 \%$ at $0.105 \mathrm{mg} /$ liter of pyraclostrobin $\left(70 \times\right.$ the $\mathrm{EC}_{50}$ of the isolates collected in 2011) and to $100 \%$ at $0.343 \mathrm{mg} / \mathrm{liter}$ of pyraclostrobin (230x and $70 \times$ the $\mathrm{EC}_{50}$ of the isolates from 2011 and 2016, respectively) (Table 2).

\section{Discussion}

Given the high risk for the development of pyraclostrobin resistance, numerous studies have evaluated the sensitivity of different phytopathogens to this fungicide. Pyraclostrobin-resistant isolates of Mycosphaerella pinodes were reported from infected field pea crops in two provinces of Canada and two states of the United States (Bowness et al. 2016). Akhavan et al. (2017) also identified an isolate of Pyrenophora teres f. maculata (net blotch of barley) from Saskatchewan with decreased sensitivity to pyraclostrobin. In contrast, isolates of Phytophthora cactorum (Lebert and Cohn) Schröeter from infected strawberry in the United States (Rebollar-Alviter et al. 2007) and isolates of Pyrenophora tritici-repentis (Died.) Drechsler from infected wheat in Canada (MacLean et al. 2017) showed no decrease in sensitivity to this compound. In Canada, pyraclostrobin was first registered on cereals, pulses, and vegetables in 2001 and then on canola in 2010 (Government of Canada, Health Canada Pest Management Regulatory Agency 2011). Limited information is available, however, on the pyraclostrobin sensitivity of L. maculans populations in Alberta. Fraser et al. (2017) evaluated the sensitivity in a collection of 117 L. maculans isolates from Alberta in 2011 but did not find any evidence of insensitivity to pyraclostrobin at that time.

Isolates with no history of exposure to a fungicide are typically used as a baseline in fungicide sensitivity studies. The isolates characterized by Fraser et al. (2017) were collected in the first year that pyraclostrobin was registered for blackleg control on canola, and hence there is some possibility that these isolates may have been exposed to the fungicide. Nonetheless, because no L. maculans isolates collected prior to the registration of pyraclostrobin in Alberta are available, the same baseline isolates used by Fraser et al. (2017) were included in the current study, along with 38 isolates randomly selected from a collection of $L$. maculans isolates made from Alberta in 2016. A two-sided paired $t$ test indicated that the $\mathrm{EC}_{50}$ values obtained by Fraser et al. (2017) were not statistically different from those calculated in this study for the same set of isolates $(P=0.29)$. The mean $\mathrm{EC}_{50}$ for the 2016 isolates was $4 \times$ greater than for the 2011 isolates. Moreover, testing with a discriminatory dose of pyraclostrobin $4 \times$ greater than the mean $\mathrm{EC}_{50}$ of the 2011 isolates found that approximately a third (80) of the isolates were inhibited $<50 \%$; at a discriminatory dose $50 \times$ greater than the mean $\mathrm{EC}_{50}$, one isolate was inhibited $<50 \%$. These results suggest that the pyraclostrobin sensitivity of $L$. maculans isolates in Alberta decreased from 2011 to 2016. Repeated use of a fungicide with the same mode of action could lead to the development of insensitivity or resistance in fungal populations (Brent and Hollomon 2007). Given that the isolates collected in 2016 may have been exposed to pyraclostrobin several more times than those collected in 2011, it is likely that the selection pressure imposed by the frequent application of this product resulted in an increase in the proportion of the L. maculans population exhibiting insensitivity. Differences in fungicide sensitivity also may be influenced by the inherent diversity in isolates from different fungal populations across a region (Kutcher et al. 2007) and/or different fungicide application regimes (Kutcher et al. 2011).

Five of the L. maculans isolates used to determine the mean $\mathrm{EC}_{50}$ of the 2016 fungal collection via the growth plate assay had predicted $\mathrm{EC}_{50}$ values greater than the maximum concentration of pyraclostrobin employed and, therefore, were excluded from the calculation of the final mean $\mathrm{EC}_{50}$. This may have led to a slight underestimation of the mean $\mathrm{EC}_{50}$ for the 2016 isolates, further supporting the conclusion that this value had increased for L. maculans between 2011 and 2016. The $\mathrm{EC}_{50}$ values obtained with the microtiter plate assay were lower than those calculated based on the conventional growth plate assay. QoIs have a direct effect on spore germination (Olaya et al. 1998), so it is expected that the $\mathrm{EC}_{50}$ values would be much lower in a microtiter plate assay compared with a growth plate assay (Bartlett et al. 2002). Because pyraclostrobin mainly suppresses conidial germination, the microtiter plate assay is likely the preferred and most sensitive method for determining the sensitivity of $L$. maculans isolates to this fungicide (Patel et al. 2012; Wise et al. 2008). Nonetheless, growth inhibition of the isolates at the two discriminatory doses evaluated, in both the conventional growth plate and microtiter plate assays, was not significantly different.

Bowness et al. (2016) observed that isolates of $M$. pinodes on field pea had extreme insensitivity to pyraclostrobin with mean $\mathrm{EC}_{50}$ values that were nearly $1,500 \times$ greater than those of sensitive isolates. Based on those observations, they suggested that qualitative insensitivity to pyraclostrobin occurs in M. pinodes (Bowness et al. 2016). Akhavan et al. (2017) reported that although some $P$. teres f. maculata isolates were insensitive to pyraclostrobin, a dosage $23 \times$ the

Table 2. The minimum inhibitory concentration of pyraclostrobin needed to inhibit mycelial growth (\%) of Leptosphaeria maculans isolate 16CW239002 in conventional growth plate and microtiter plate assays

\begin{tabular}{lcccc}
\hline \multicolumn{2}{c}{$\begin{array}{c}\text { Conventional growth plate assays } \\
\text { Concentration }\end{array}$} & & \multicolumn{2}{c}{ Microtiter plate assays } \\
\cline { 5 - 5 } $\begin{array}{c}\text { Percent growth } \\
\text { inhibition }\end{array}$ & & $\begin{array}{c}\text { Concentration } \\
\text { (mg/liter) }\end{array}$ & $\begin{array}{c}\text { Percent growth } \\
\text { inhibition }\end{array}$ \\
\hline 4.9 & $71.83 \%$ & & 0.105 & $75.39 \%$ \\
7 & $87.55 \%$ & & 0.15 & $80.4 \%$ \\
10.5 & $92.21 \%$ & & 0.225 & $94.32 \%$ \\
14 & $98.81 \%$ & & 0.245 & $98.97 \%$ \\
19.6 & $100.00 \%$ & & 0.343 & $100.00 \%$ \\
28 & $100.00 \%$ & & 0.49 & $100.00 \%$ \\
42 & $100.00 \%$ & 0.735 & $100.00 \%$ \\
\hline
\end{tabular}


average $\mathrm{EC}_{50}$ could still inhibit growth of all isolates by $>50 \%$. This led these researchers to conclude that the $P$. teres $\mathrm{f}$. maculata isolates had quantitative insensitivity to pyraclostrobin (Akhavan et al. 2017). Based on the current results, only one isolate (16CW239002) appeared to be insensitive to pyraclostrobin. Nonetheless, this isolate failed to grow at a discriminatory dose $70 \times$ the $\mathrm{EC}_{50}$ of isolates collected in 2016 (280x and $230 \times$ the $\mathrm{EC}_{50}$ of the isolates from 2011 in growth plate and microtiter plate assays, respectively), suggesting this isolate may be tolerant or quantitatively resistant to pyraclostrobin. Three amino acid substitutions, G143A, G137R, and F129L in cytochrome $b$ may contribute to resistance or tolerance to QoI fungicides (Grasso et al. 2006; Sierotzki and Frey 2007). Further studies are necessary to determine whether any of the known mutation(s) are associated with this observed insensitivity. Indeed, because the mutations associated with pyraclostrobin insensitivity in L. maculans have not been characterized to date, the molecular basis underlying the observed insensitivity should be explored.

To the best of our knowledge, this is the first report of L. maculans isolates exhibiting decreased sensitivity to pyraclostrobin. Nonetheless, although insensitivity to pyraclostrobin has not been reported previously in this pathogen, Van de Wouw et al. (2017) found that the sensitivity of Australasian isolates of $L$. maculans to fluquinconazole has also decreased. This suggests the potential for multiple resistance issues in this important fungus and highlights the need for judicious use of fungicides in the management of blackleg of canola. Strategies such as the rotation of fungicides with different modes of action, along with the adoption of cultural and other control methods as part of an integrated disease management plan, will be important for the sustainable and long-term mitigation of blackleg.

\section{Acknowledgments}

In-kind support from Alberta Agriculture and Forestry and the University of Alberta is gratefully acknowledged.

\section{Literature Cited}

Akhavan, A., Strelkov, S. E., Askarian, H., Kher, S. V., Fraser, M., Kutcher, H. R., and Turkington, T. K. 2017. Sensitivity of western Canadian Pyrenophora teres f. teres and $P$. teres f. maculata isolates to propiconazole and pyraclostrobin. Can. J. Plant Pathol. 39:11-24.

Bartlett, D. W., Clough, J. M., Godwin, J. R., Hall, A. A., Hamer, M., and ParrDobrzanski, B. 2002. The strobilurin fungicides. Pest Manag. Sci. 58:649-662.

BASF. 2018. Headline ${ }^{\circledR}$ Fungicide. https://agriculture.basf.us/crop-protection/ products/headline.html.

Bowness, R., Gossen, B. D., Chang, K., Goswani, R., Willenborg, C. J., Holtz, M., and Strelkov, S. E. 2016. Sensitivity of Mycosphaerella pinodes to pyraclostrobin fungicide. Plant Dis. 100:192-199.

Brent, K. J., and Hollomon, D. W. 2007. Fungicide resistance in crop pathogens: How can it be managed? 2nd Ed. Fungicide Resistance Action Committee, Belgium. https://www.frac.info/docs/default-source/publications/monographs/ monograph-1.pdf?sfvrsn $=8$

Canola Council of Canada. 2017. Blackleg Management. https://www.canolacouncil. org/canola-encyclopedia/diseases/blackleg/blackleg-management/.

Fitt, B. D., Brun, H., Barbetti, M. J., and Rimmer, S. R. 2006. World-wide importance of Phoma stem canker (Leptosphaeria maculans and L. biglobosa) on oilseed rape (Brassica napus). Eur. J. Plant Pathol. 114:3-15.

Forcelini, B. B., Seijo, T. E., Amiri, A., and Peres, N. A. 2016. Resistance in strawberry isolates of Colletotrichum acutatum from Florida to quinoneoutside inhibitor fungicides. Plant Dis. 100:2050-2056.

Fraser, M., Hwang, S., Ahmed, H. U., Akhavan, A., Stammler, G., Barton, W. R., and Strelkov, S. 2017. Sensitivity of Leptosphaeria maculans to pyraclostrobin in Alberta, Canada. Can. J. Plant Sci. 97:83-91.

Gisi, U., Sierotzki, H., Cook, A., and McCaffery, A. 2002. Mechanisms influencing the evolution of resistance to Qo inhibitor fungicides. Pest Manag. Sci. 58:859-867.

Government of Canada, Health Canada Pest Management Regulatory Agency. 2011. Archived - Pyraclostrobin seed treatment - Proposed registration decision PRD2011-15 - Health Canada consultation document. https://www.canada.ca/ en/health-canada/services/consumer-product-safety/pesticides-pest-management/ public/consultations/pyraclostrobin-seed-treatment-proposed-registrationdecision-prd2011-15-health-canada-consultation-document.html.

Grasso, V., Palermo, S., Sierotzki, H., Garibalid, A., and Gisi, U. 2006 Cytochrome $b$ gene structure and consequences for resistance to Qo inhibitor fungicides in plant pathogens. Pest Manag. Sci. 62:465-472.

Gugel, R., and Petrie, G. 1992. History, occurrence, impact, and control of blackleg of rapeseed. Can. J. Plant Pathol. 14:36-45.

Health Canada. 2003. Pyraclostrobin, Headline EC, Cabrio EG. http://publications.gc.ca/ site/archivee-archived.html?url=http://publications.gc.ca/collections/Collection/H1137-2003-6E.pdf.

Howlett, B. J. 2004. Current knowledge of the interaction between Brassica napus and Leptosphaeria maculans. Can. J. Plant Pathol. 26:245-252.

Hwang, S., Strelkov, S., Peng, G., Ahmed, H., Zhou, Q., and Turnbull, G. 2016. Blackleg (Leptosphaeria maculans) severity and yield loss in canola in Alberta, Canada. Plants 5:31.

Inoue, K., Tsurumi, T., Ishii, H., Park, P., and Ikeda, K. 2012. Cytological evaluation of the effect of azoxystrobin and alternative oxidase inhibitors in Botrytis cinerea. FEMS Microbiol. Lett. 326:83-90.

Kutcher, H. R., Brandt, S. A., Smith, E. G., Ulrich, D., Malhi, S. S., and Johnston, A. M. 2013. Blackleg disease of canola mitigated by resistant cultivars and fouryear crop rotations in western Canada. Can. J. Plant Pathol. 35:209-221.

Kutcher, H. R., Fernando, W. G. D., Turkington, T. K., and McLaren, D. L. 2011. Best management practices for blackleg disease of canola. Prairie Soils Crops J. 4:122-134.

Kutcher, H. R., Keri, M., McLaren, D. L., and Rimmer, S. R. 2007. Pathogenic variability of Leptosphaeria maculans in western Canada. Can. J. Plant Pathol. 29:388-393.

MacLean, D. E., Aboukhaddour, R., Tran, V. A., Askarian, H., Strelkov, S. E., Turkington, T. K., and Kutcher, H. R. 2017. Race characterization of Pyrenophora tritici-repentis and sensitivity to propiconazole and pyraclostrobin fungicides. Can. J. Plant Pathol. 39:433-443.

Olaya, G., Zheng, D., and Köller, W. 1998. Differential responses of germinating Venturia inaequalis conidia to kresoxim-methyl. Pestic. Sci. 54:230-236.

Patel, J. S., Gudmestad, N. C., Meinhardt, S., and Adhikari, T. B. 2012. Pyraclostrobin sensitivity of baseline and fungicide exposed isolates of Pyrenophora tritici-repentis. Crop Prot. 34:37-41.

R Core Team. 2013. R: A Language and Environment for Statistical Computing. R Foundation for Statistical Computing, Vienna, Austria.

Rebollar-Alviter, A., Madden, L. V., Jeffers, S. N., and Ellis, M. A. 2007. Baseline and differential sensitivity to two QoI fungicides among isolates of Phytophthora cactorum that cause leather rot and crown rot on strawberry. Plant Dis. 91:1625-1637.

Rong, S., Feng, J., Li, Q., Fei, W., Ahmed, H. U., Liang, Y., Hwang, S. F., and Strelkov, S. E. 2015. Pathogenic variability and prevalence of Avr genes in Leptosphaeria maculans populations from Alberta, Canada. J. Plant Dis. Prot. 122:161-168

Sierotzki, H., and Frey, R. 2007. Cytochrome $b$ gene sequence and structure of Pyrenophora teres and P. tritici-repentis and implications for QoI resistance. Pest Manag. Sci. 63:225-233.

Spiegel, J., and Stammler, G. 2006. Baseline sensitivity of Monilinia laxa and M. fructigena to pyraclostrobin and boscalid. J. Plant Dis. Prot. 113: 199-206.

Van de Wouw, A. P., Elliott, V. L., Chang, S., López-Ruiz, F. J., Marcroft, S. J., and Idnurm, A. 2017. Identification of isolates of the plant pathogen Leptosphaeria maculans with resistance to the triazole fungicide fluquinconazole using a novel in planta assay. PloS One 12:e0188106.

Vincelli, P. 2002. QoI (strobilurin) fungicides: Benefits and risks. Plant Health Instr. doi: 10.1094/phi-i-2002-0809-02. https://www.apsnet.org/edcenter/ disimpactmngmnt/topc/Pages/StrobilurinFungicides.aspx

West, J. S., Kharbanda, P. D., Barbetti, M. J., and Fitt, B. D. 2001. Epidemiology and management of Leptosphaeria maculans (Phoma stem canker) on oilseed rape in Australia, Canada and Europe. Plant Pathol. 50:10-27.

Wise, K. A., Bradley, C. A., Pasche, J. S., Gudmestad, N. C., Dugan, F. M., and Chen, W. 2008. Baseline sensitivity of Ascochyta rabiei to azoxystrobin, pyraclostrobin, and boscalid. Plant Dis. 92:295-300.

Wood, P. M., and Hollomon, D. W. 2003. A critical evaluation of the role of alternative oxidase in the performance of strobilurin and related fungicides acting at the Qo site of complex III. Pest Manag. Sci. 59: 499-511.

Zhang, X., and Fernando, W. G. D. 2017. Insights into fighting against blackleg disease of Brassica napus in Canada. Crop Pasture Sci. 69:40-47. 